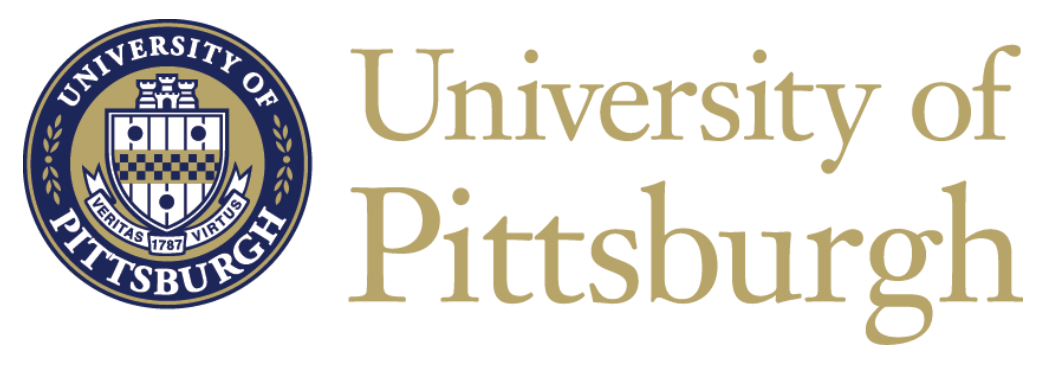

\title{
Adventitious Hydrocarbons and the Graphite-Water Interface
}

Justin Hurst

April 2020 


\section{Electrical Energy Storage}

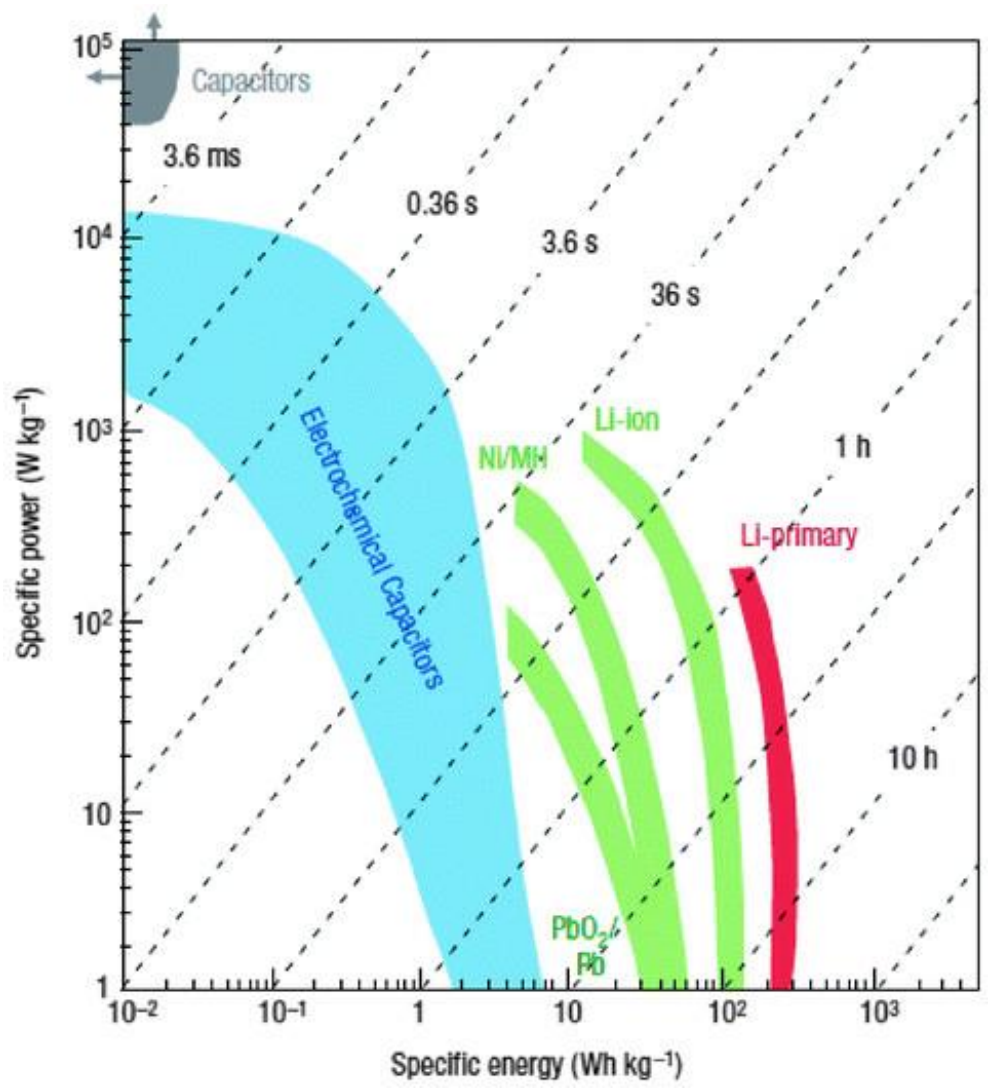

Advantages of electrochemical capacitors:

- Better charge/discharge cycle life than batteries

- Faster charging

- More power density

- Higher charge/discharge efficiency

Disadvantages of electrochemical capacitors:

- Low energy density

- Faster self-discharge rate 


\section{Carbon Electrode Materials}

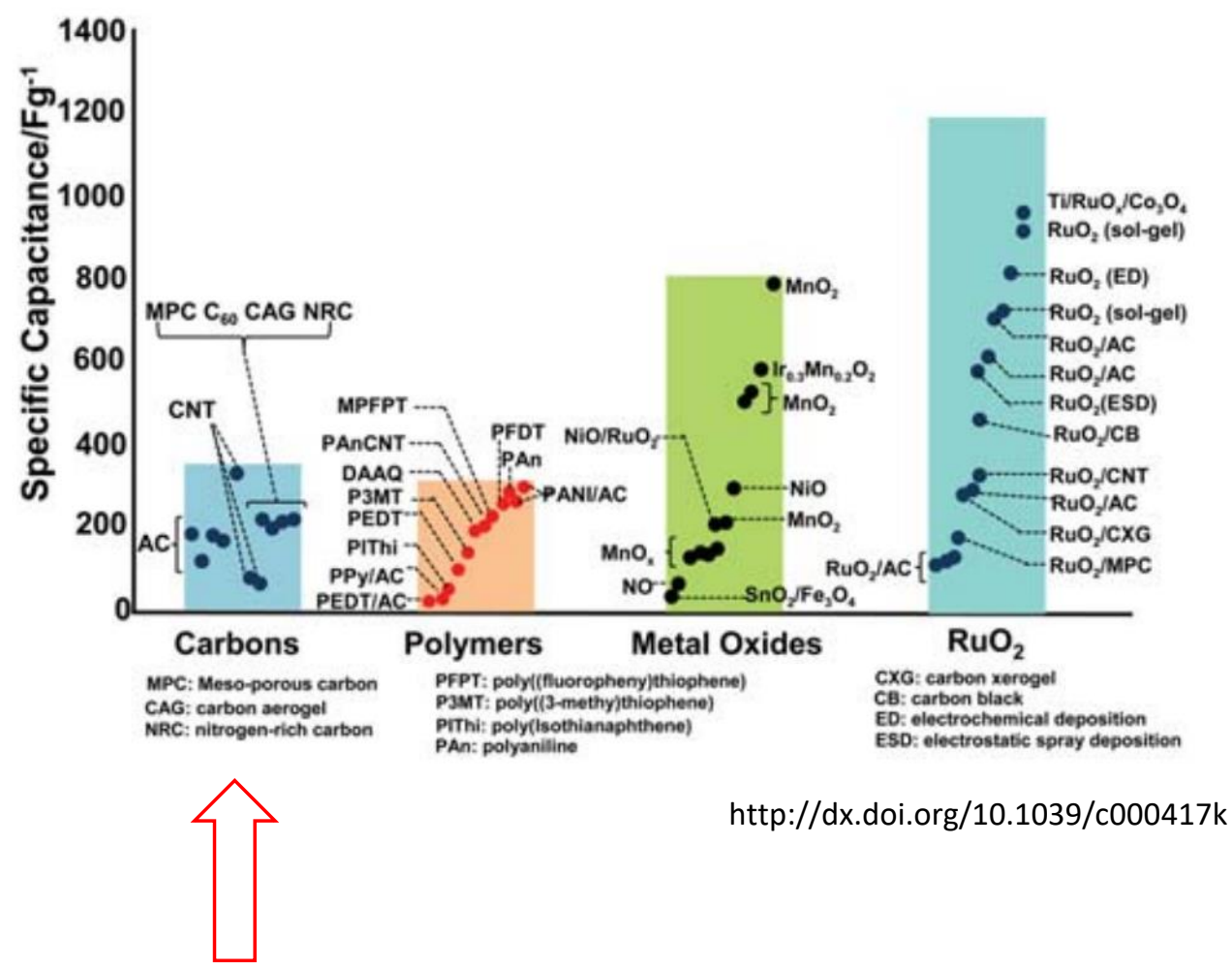

- Less expensive alternative

- Lightweight

- Materials are less toxic 


\section{Surface Contamination}

\section{We could enhance performance by using cleaner surfaces}

- Understanding the intrinsic water wettability of graphite ${ }^{1}$

- Effect of airborne contaminants on the wettability of supported graphene and graphite ${ }^{2}$

- Contamination and Wettability: Rare Earth Oxides ${ }^{3}$

1. Kozbial, A.; Li, Z.; Sun, J.; Gong, X.; Zhou, F.; Wang, Y.; Xu, H.; Liu, H.; Li, L., Understanding the intrinsic water wettability of graphite. Carbon 2014, 74, $218-225$.

2. Li, Z.; Wang, Y.; Kozbial, A.; Shenoy, G.; Zhou, F.; McGinley, R.; Ireland, P.; Morganstein, B.; Kunkel, A.; Surwade, S. P., Effect of airborne contaminants on the wettability of supported graphene and graphite. Nature materials 2013, 12 (10), 925-931. 


\section{Change in Capacitance with Air Aging}
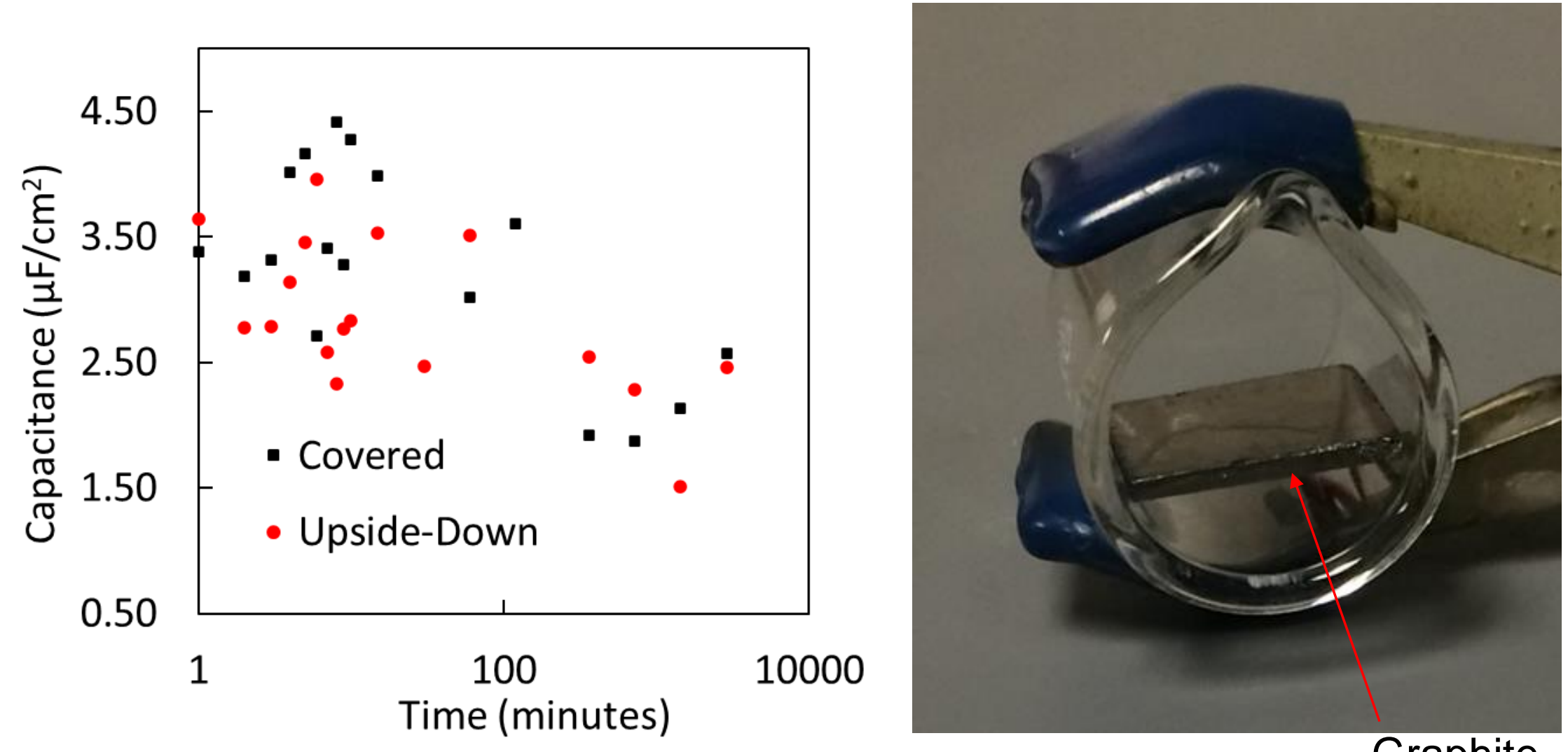

Graphite

- Clean graphite was exposed to air for different time intervals

- Each measurement is a separate exfoliation

- Capacitance reduced by $40 \%$ over 24 hours 


\section{Air Aging With 1-Octadecene}

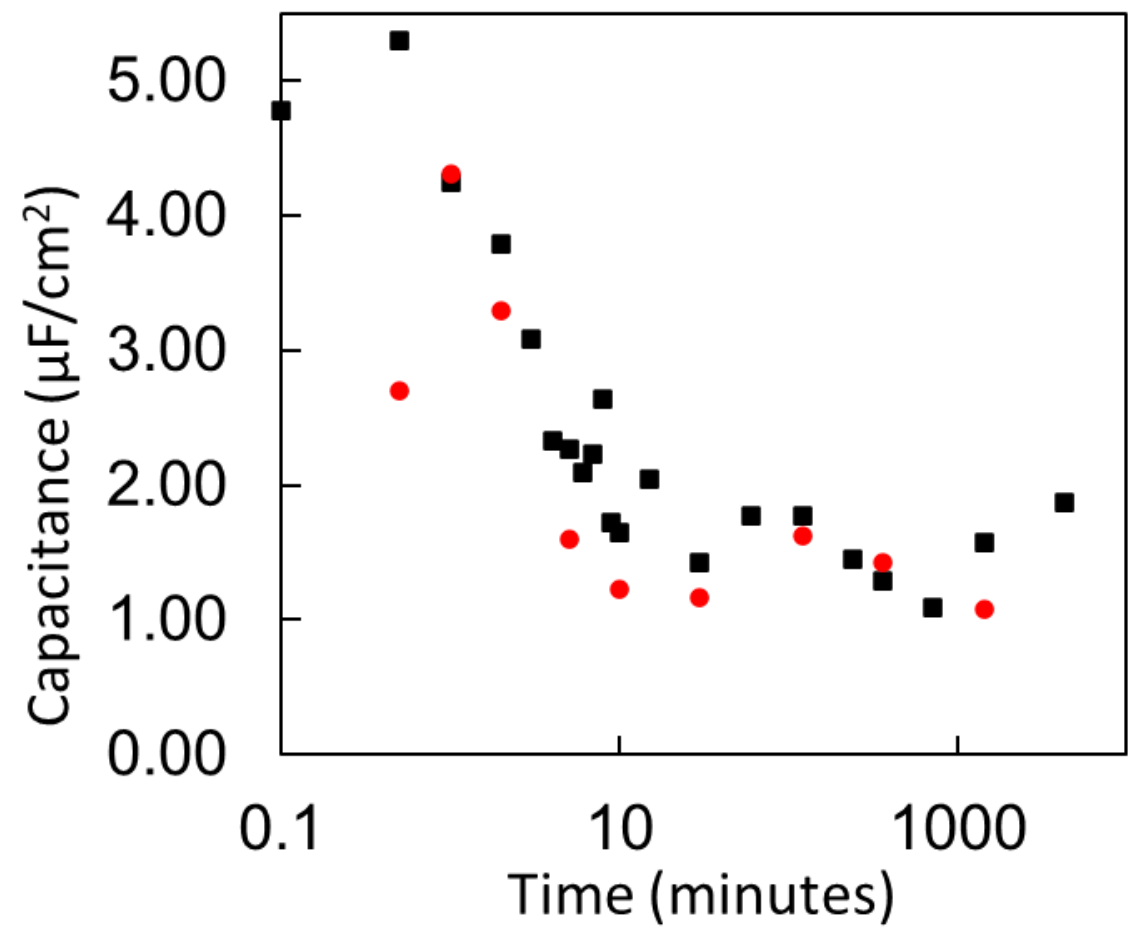

- Clean graphite was exposed to 1-octadecene environment

- Each measurement is a separate exfoliation

- Capacitance reduced by $70 \%$ over 10 minutes
1-Octadecene Reservoir
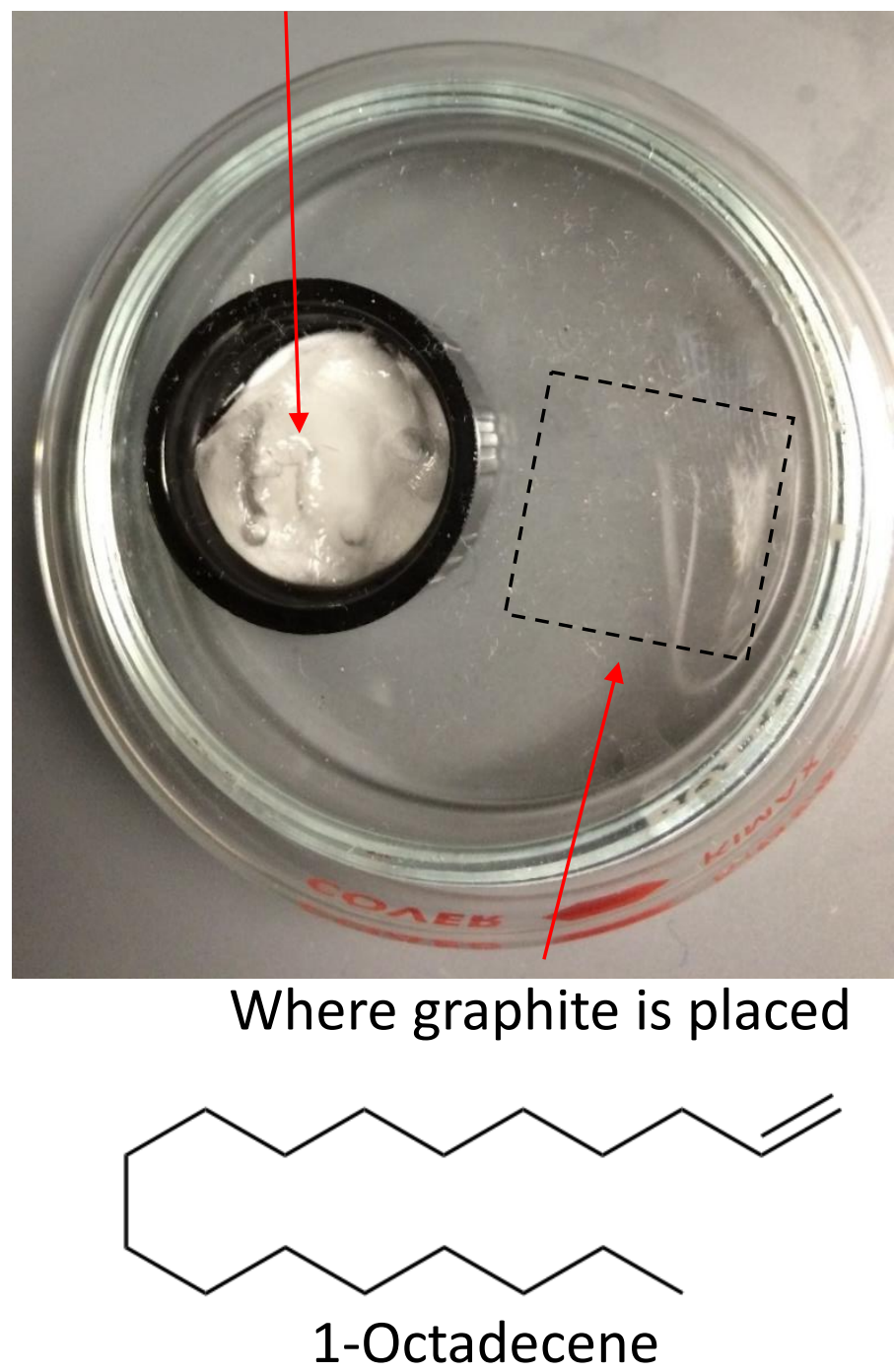


\section{FTIR of Graphite After Exposure to Air}

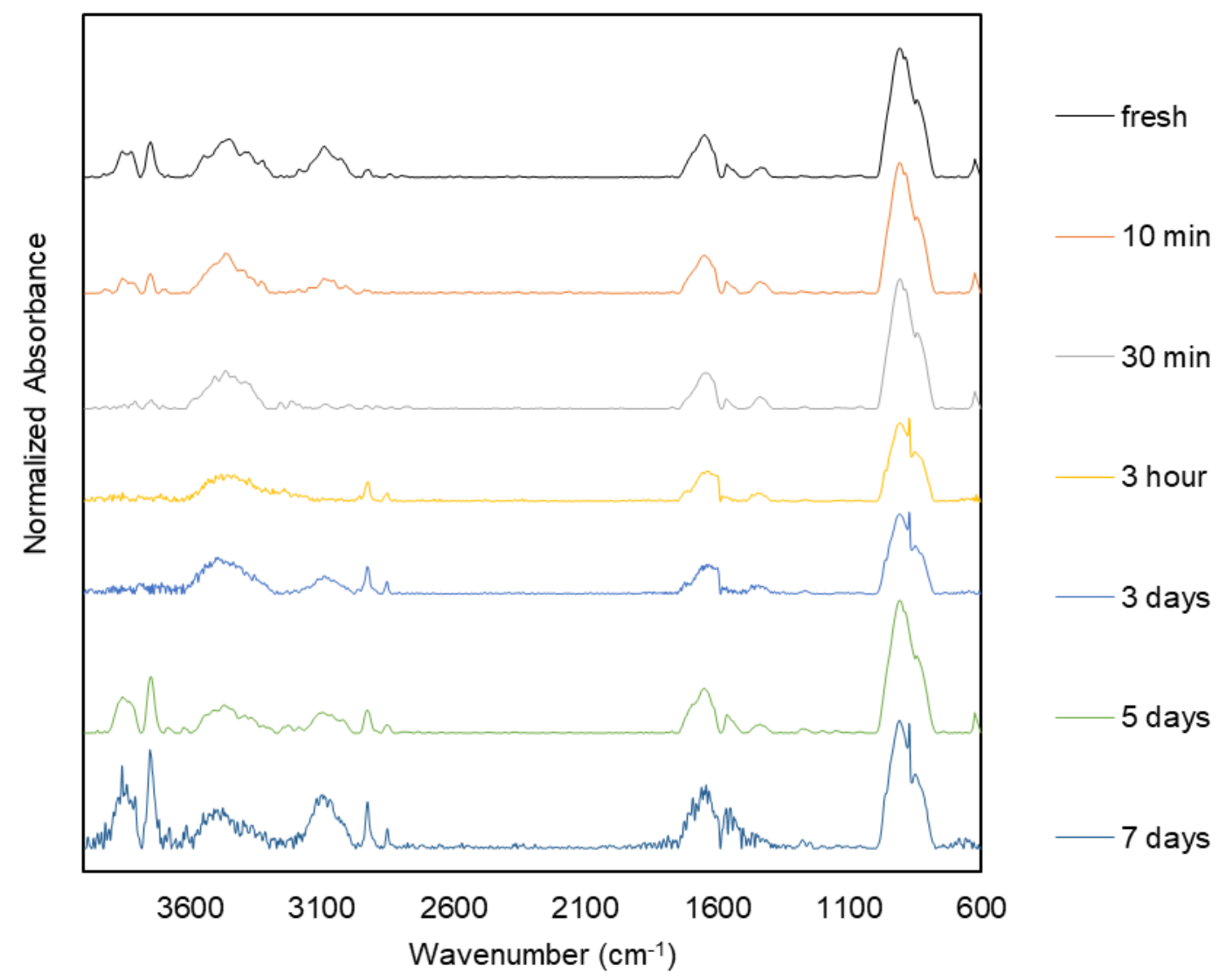

- Clean graphite was exposed to air for 4 hours

- After 10 minutes a C-H stretch peak is visible at $\sim 2900 \mathrm{~cm}^{-1}$

- A large peak at $\sim 1650 \mathrm{~cm}^{-1}$ is likely a $\mathrm{C}=\mathrm{C}$ stretch. There is little noticeable change in this peak over the duration 


\section{Exposure to 1-Octadecene}

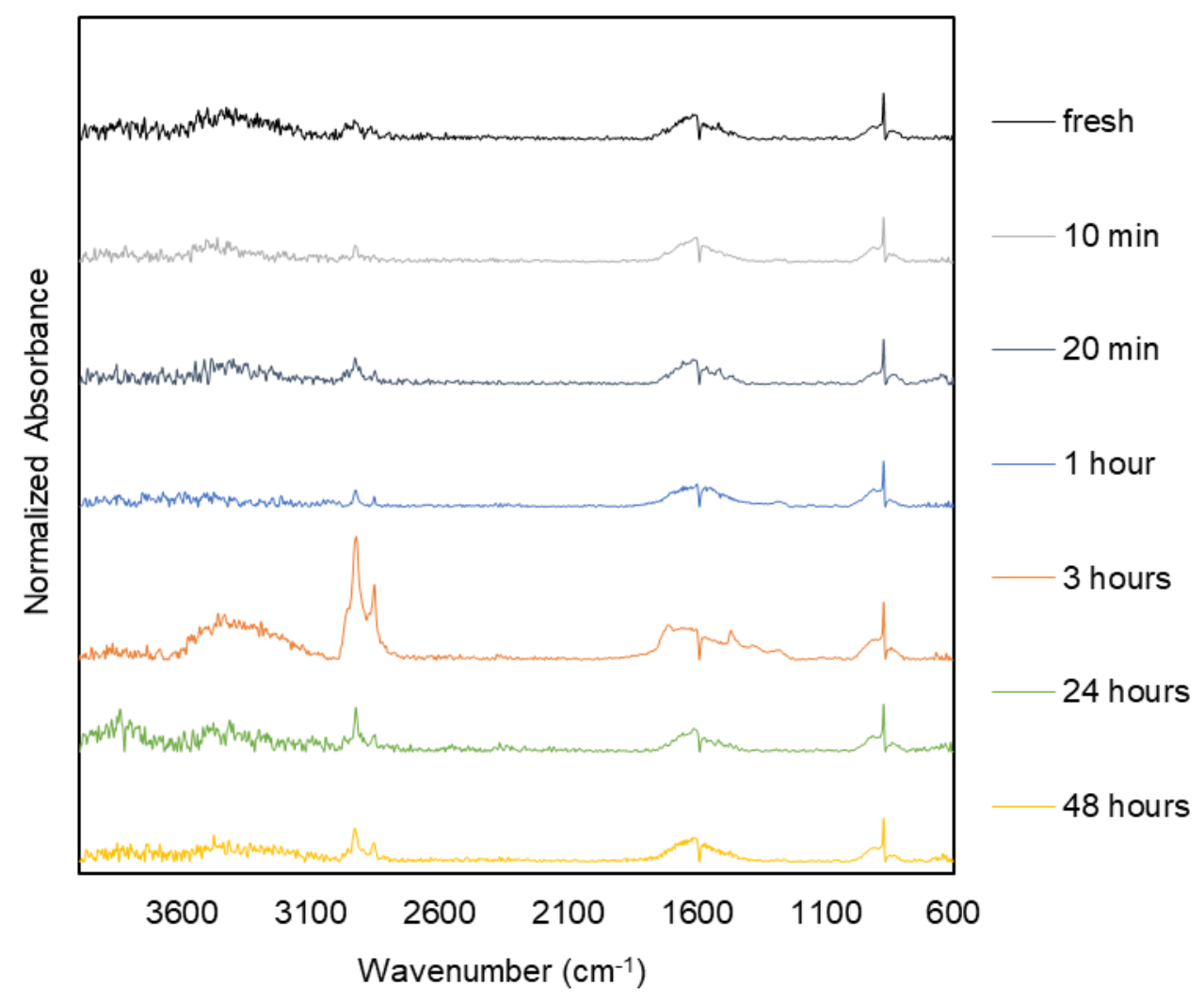

- First visible at 10 minutes

- Large increase after 3 hours - anomaly could not be replicated

- C-H stretch peaks still present after 2 days 


\section{Liquid Phase Aging}
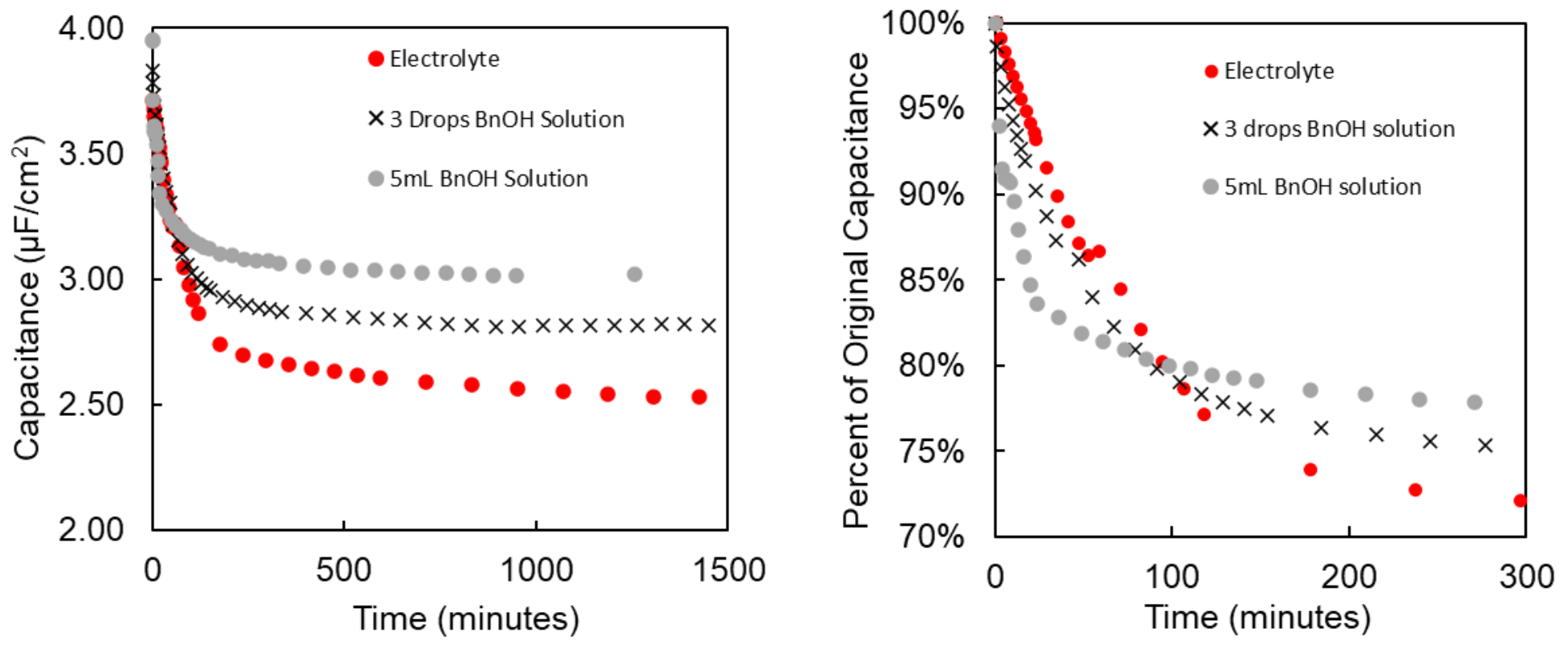

- Comparison of graphite in pure and intentionally contaminated electrolyte solution

- Initial drop in capacitance is faster with more benzyl alcohol

- Addition of $1.5 \%$ benzyl alcohol reduces the impact of contamination

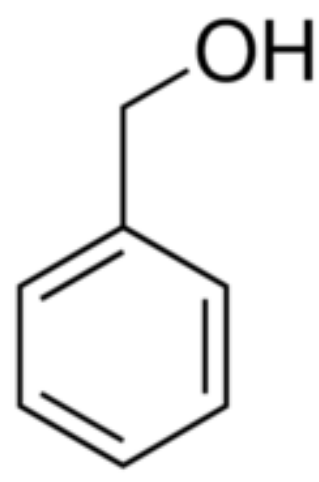




\section{Cell Potential Conditioning}

$0.778 \mathrm{~V}$

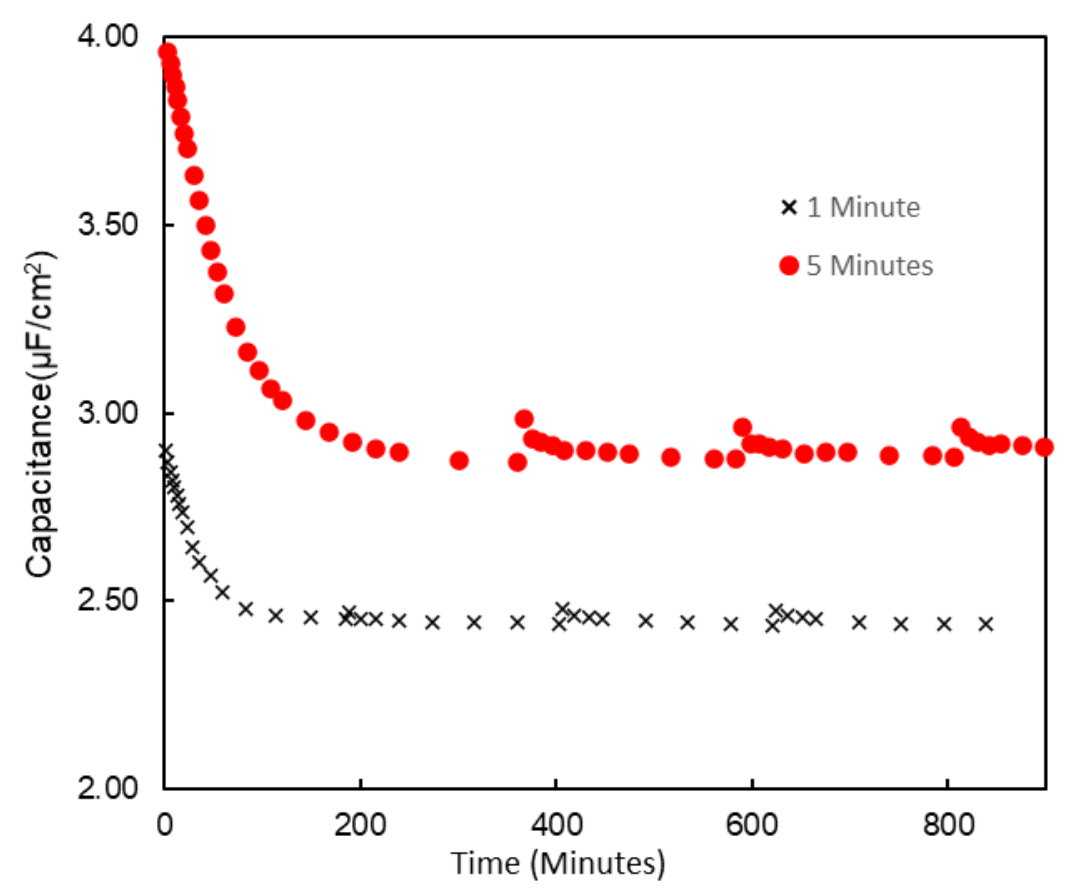

$-1.222 \mathrm{~V}$

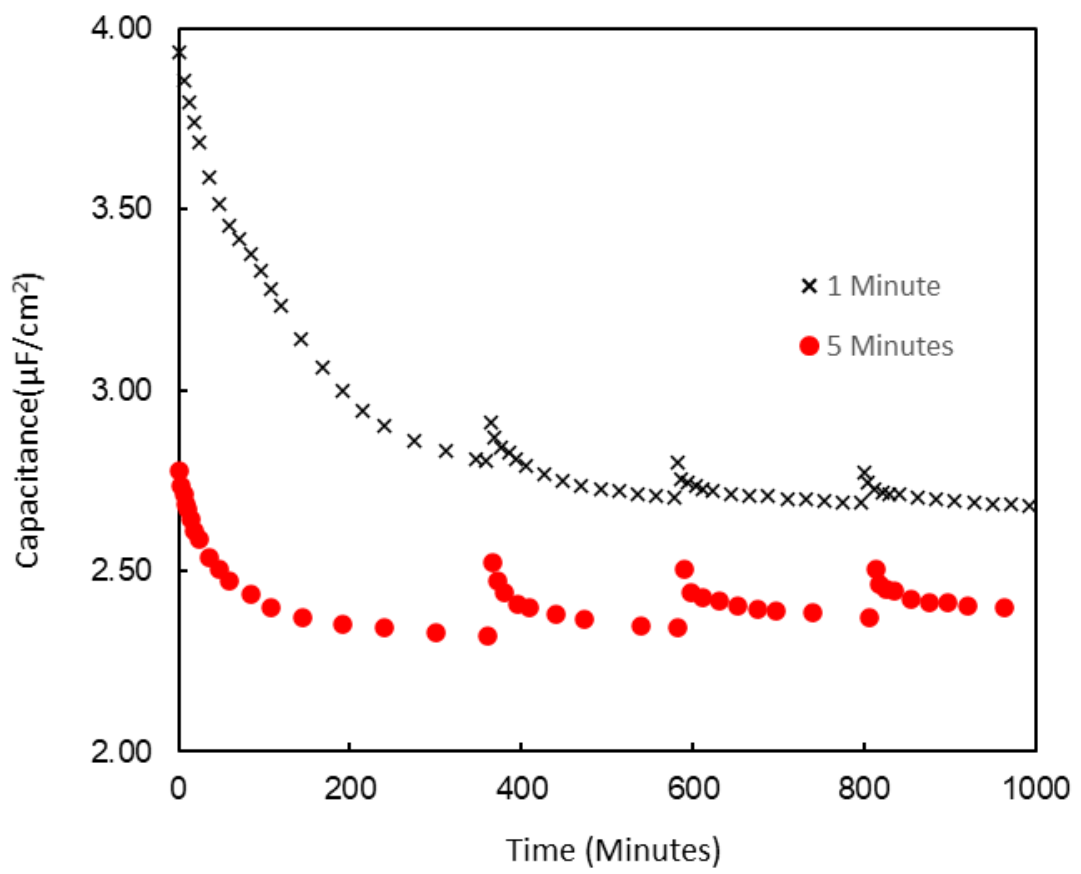

- Investigated the effect of cell potential on the equilibrium capacitance

- The cell was held at $0.778 \mathrm{~V}$ or $-1.222 \mathrm{~V}$, for either 1 minute or 5 minutes

- Capacitance measurements were taken at $-0.222 \mathrm{~V}$ 


\section{Aging at Different Cell Potentials}
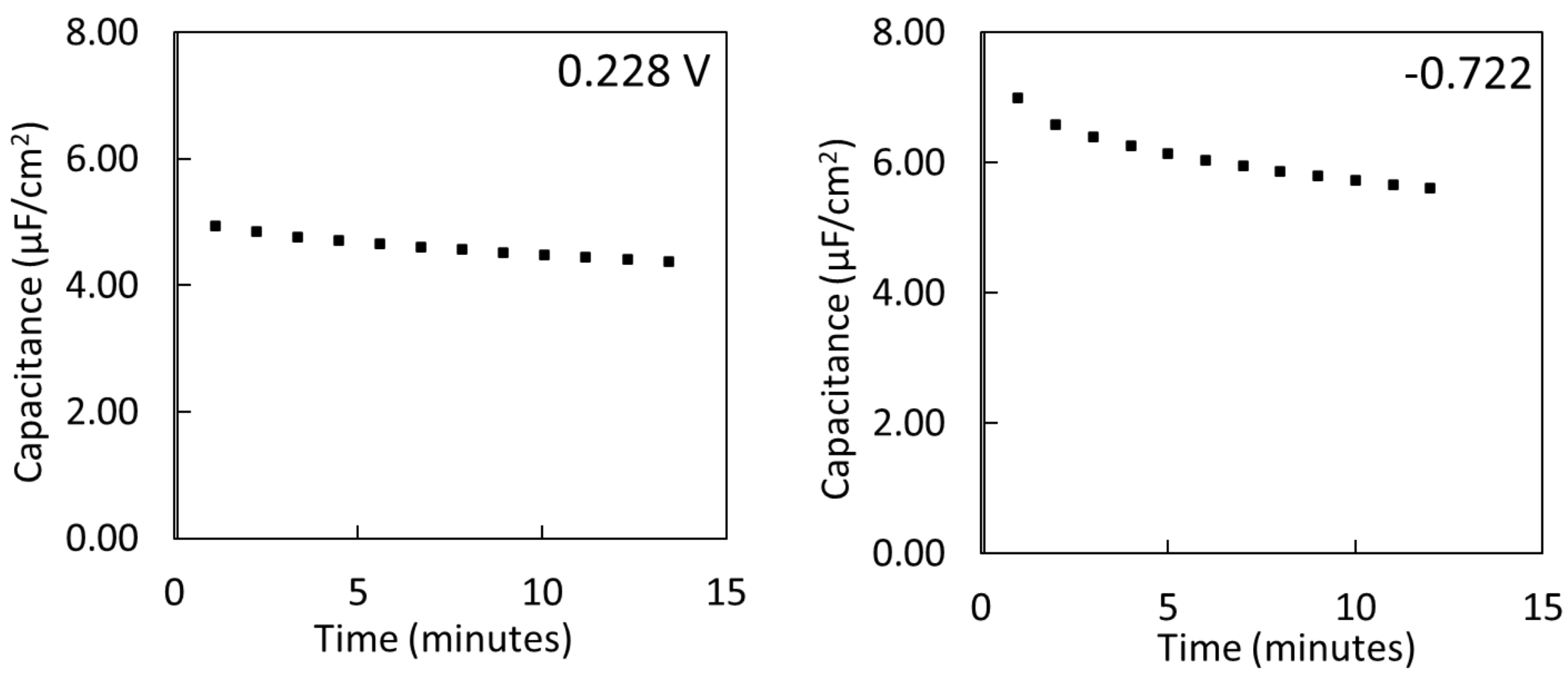

- The aging effect is observed at different cell potentials as well

- Higher initial capacitance, but sharper decrease with negative cell potential 


\section{Layer Growth in Ultrapure Water}

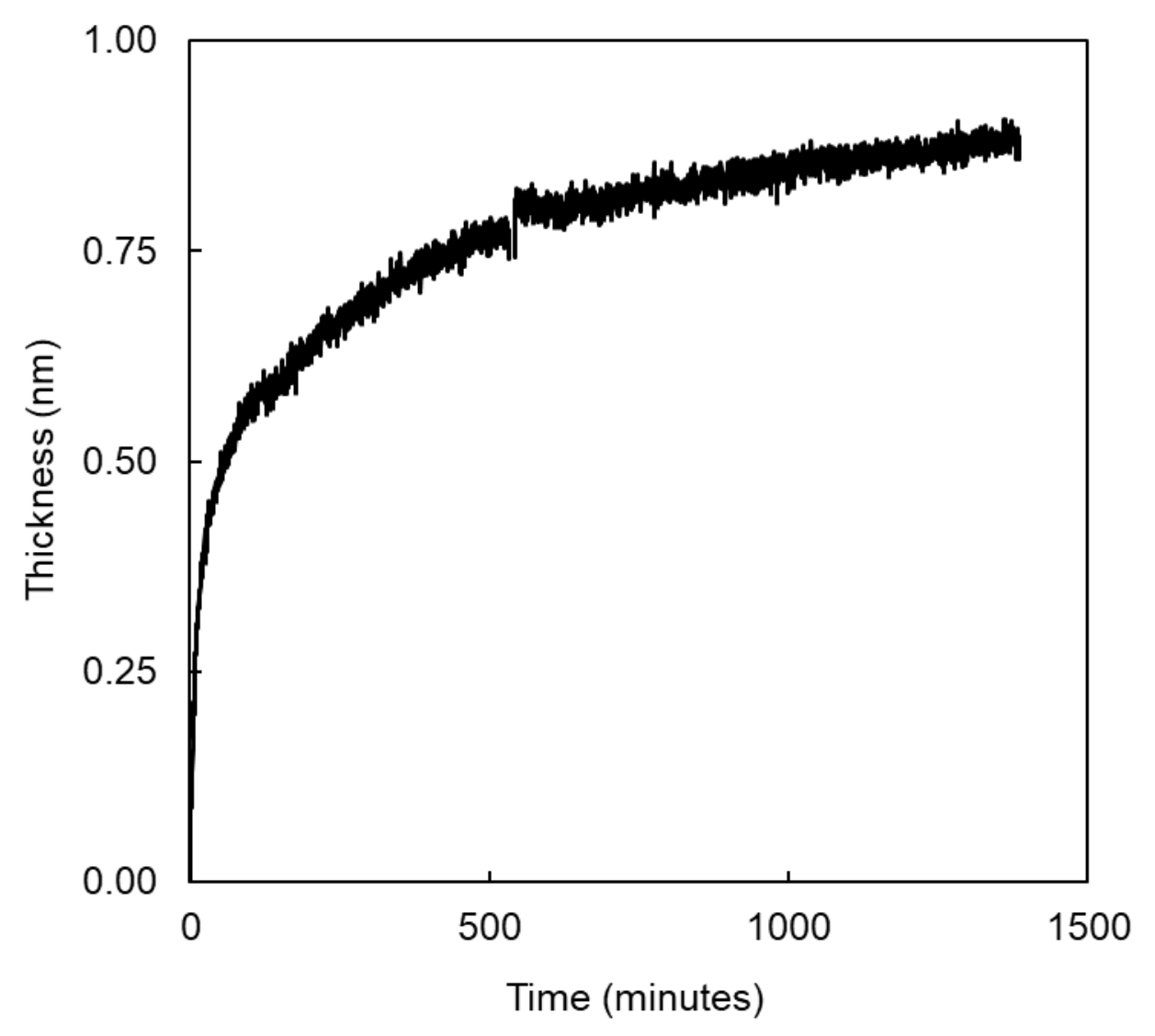

- Clean graphite in ultrapure water

- Implements rinsed with acetone, isopropyl alcohol, and water

- $0.8 \mathrm{~nm}$ layer grows in 16 hours 


\section{Layer Growth in Ultrapure Water}

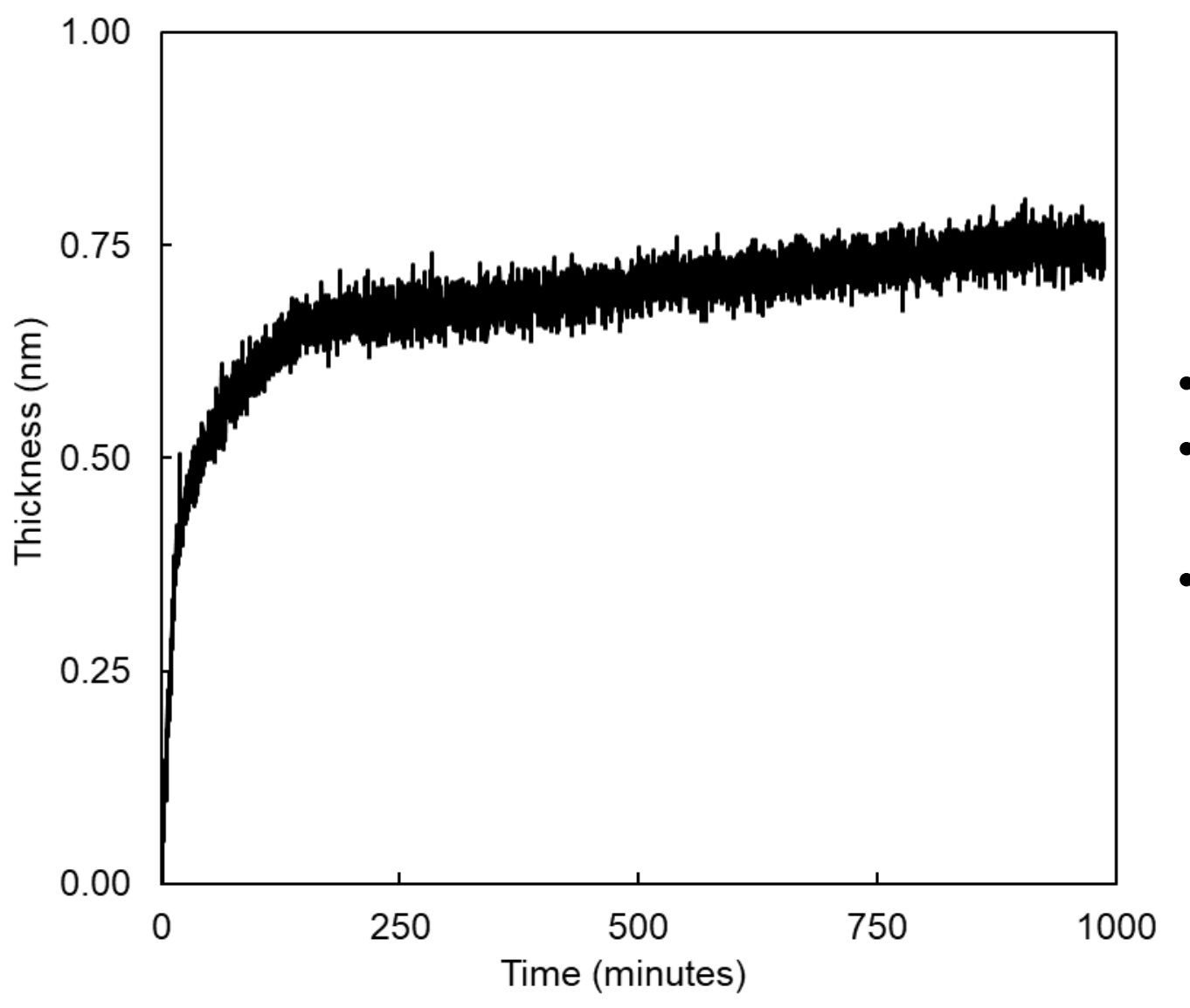

- Clean graphite in ultrapure water

- Implements cleaned with either piranha solution or UV/Ozone

- $0.75 \mathrm{~nm}$ layer grows over 16 hours 


\section{Layer Growth with Added Stearic Acid}

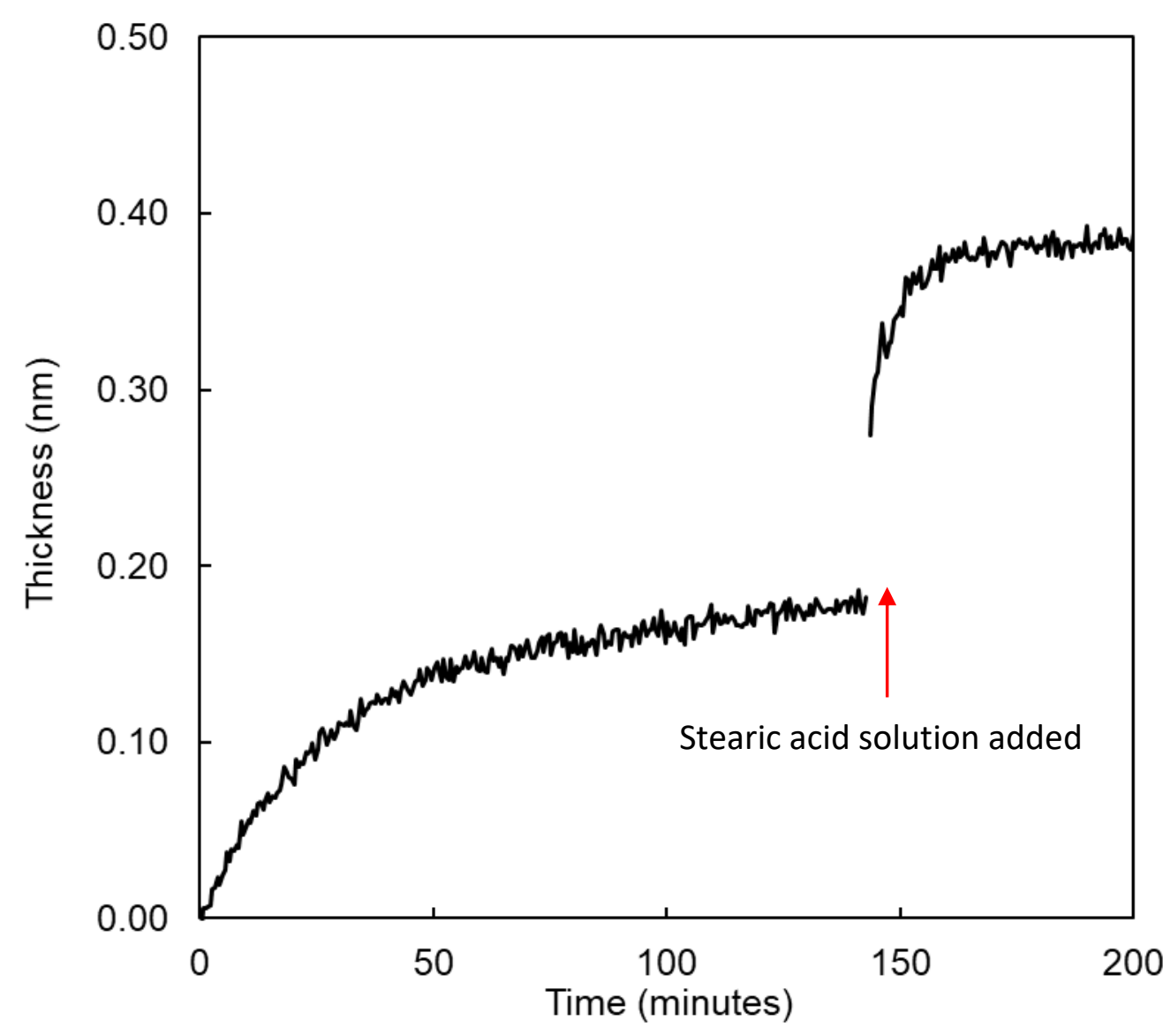

- Clean graphite in ultrapure water

- Saturated stearic acid solution added $\left(\sim 10^{-2} \mathrm{M}\right)$ around 140 minutes

- Rapid layer growth of an additional $0.2 \mathrm{~nm}$ over one hour.

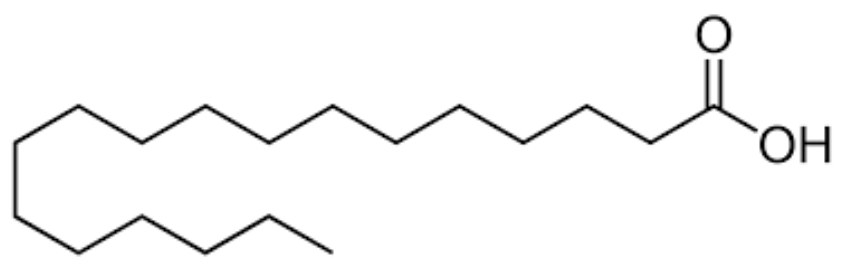




\section{Layer Growth with Added Stearic Acid}

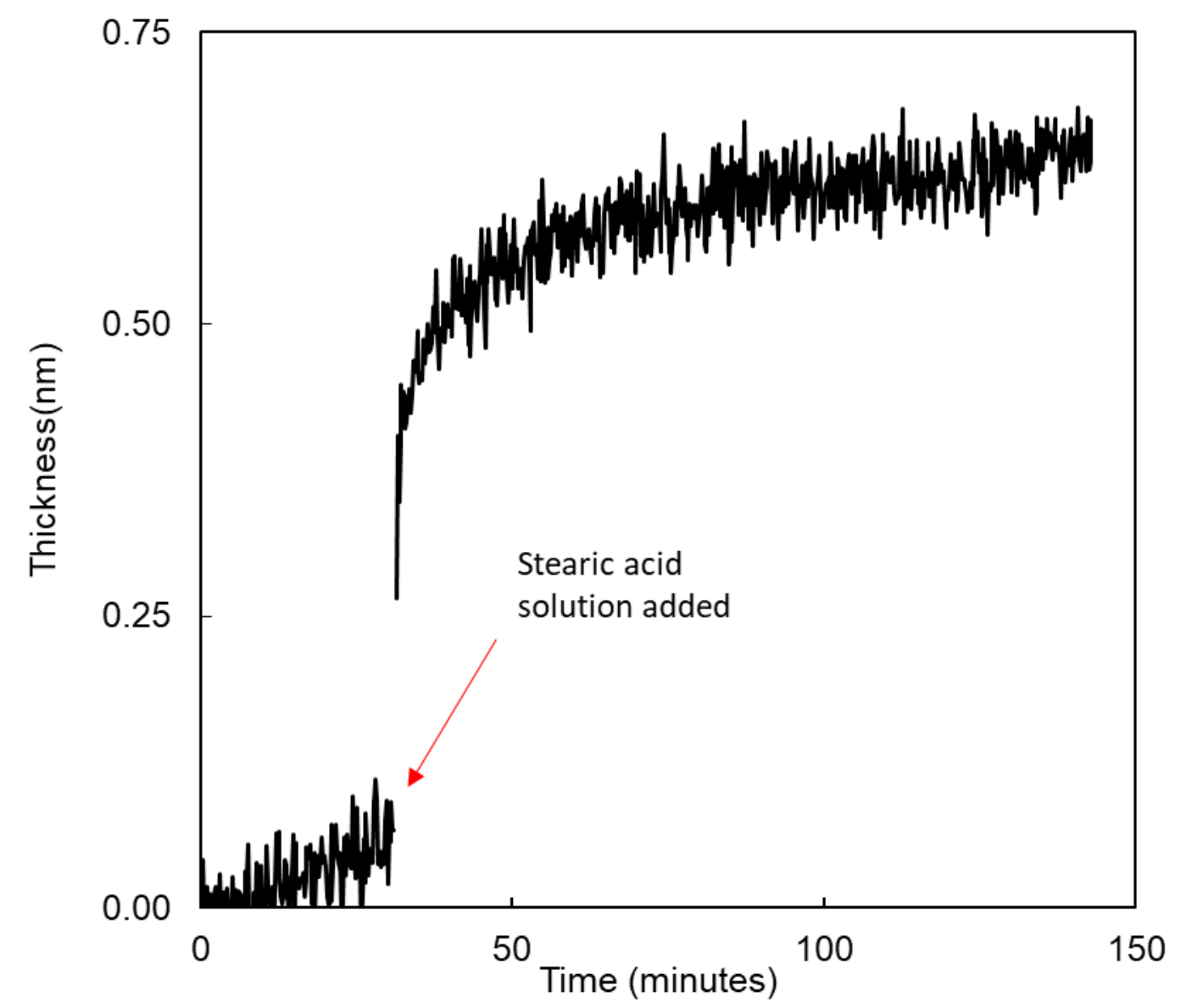

- Clean graphite in ultrapure water

- Saturated stearic acid solution added $\left(\sim 10^{-2} \mathrm{M}\right)$ around 140 minutes

- Rapid layer growth of an additional $0.6 \mathrm{~nm}$ over one hour. 


\section{Layer Growth in Electrolyte Solution}

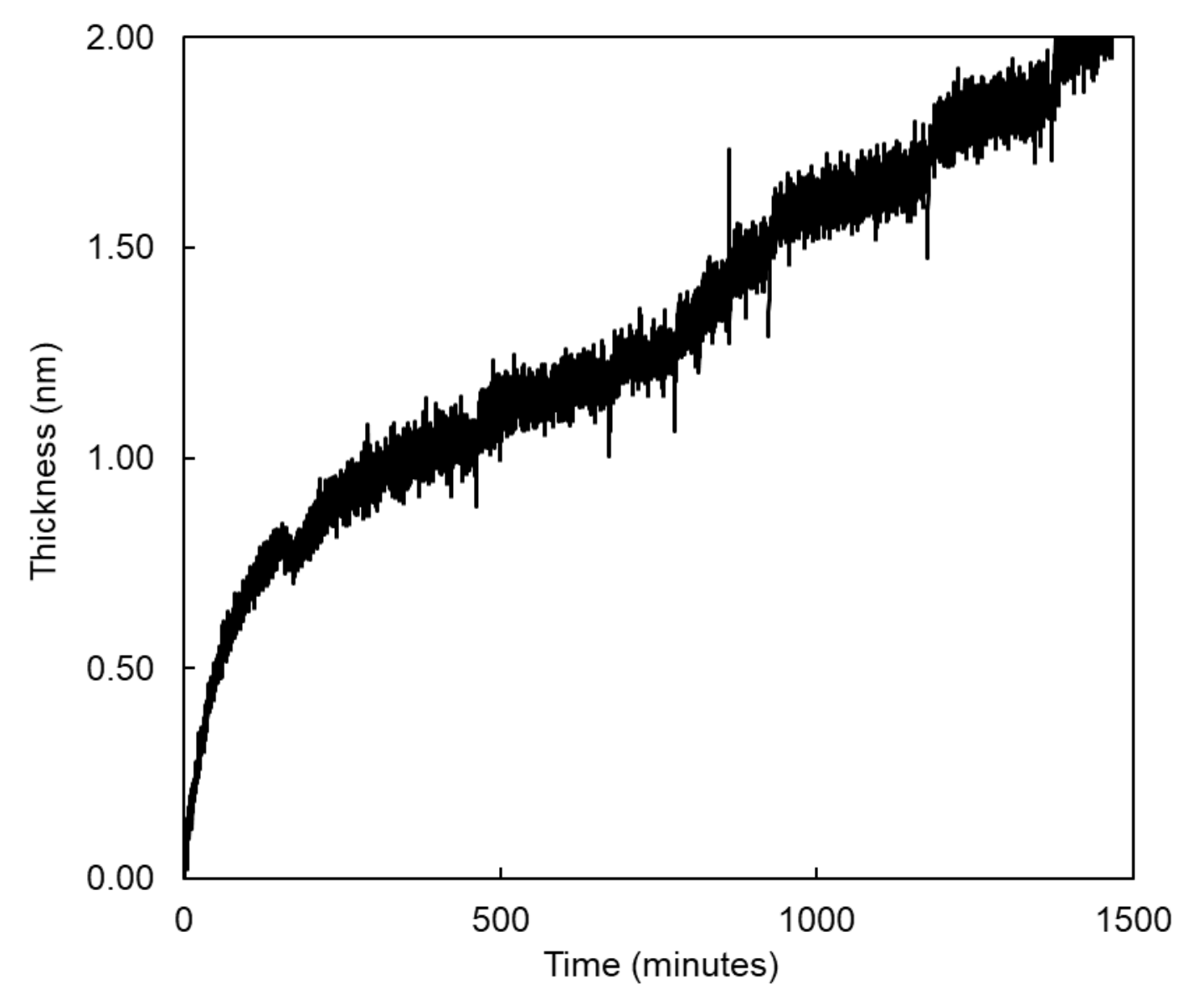

- Clean graphite in electrolyte solution

- A 2 nm layer grows over 16 hours

- The electrolyte used adds contamination as well 


\section{Conclusions}

- Contamination from air can reduce the capacitance in as little as 10 minutes

- Intentional contamination reduced the capacitance by as much as $70 \%$

- Water borne contamination from the electrolyte reduced the capacitance by about $30 \%$

- Ellipsometry showed that about $\sim 0.5 \mathrm{~nm}$ of contamination can grow within an hour in water or electrolyte.

- FTIR studies showed the existence of hydrocarbons on the surface within the appropriate timeframe 


\section{Future Directions}

Confirming the contamination effect on other carbon materials:

- Graphene

- Activated carbon

- Carbon nanotubes

Investigating the behavior of a manufactured carbon capacitor:

- Double layer/Electrolytic

- Aqueous/ionic liquid

Determination of a dielectric material to competitively inhibit adsorption of contaminants on carbon surfaces 


\section{Acknowledgements}

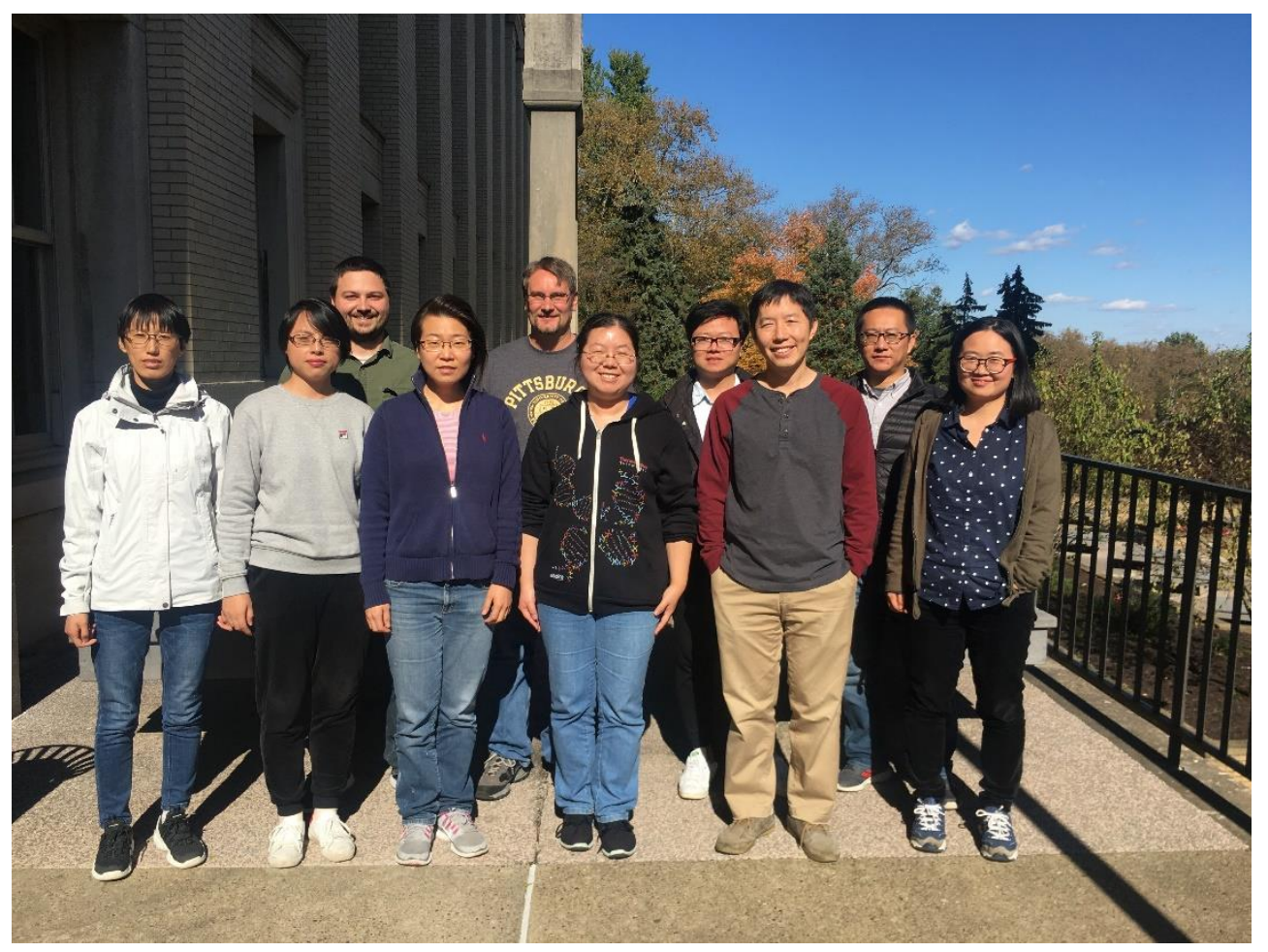

Dr. Haitao Liu \& group members.

Prof. Shigeru Amemiya and Dr. Andrew Kozbial for helpful comments and assistance.

This work is supported in part by ONR (N00014-15-1-2520). 